\title{
Maturation of mast cell progenitors to mucosal mast cells during allergic pulmonary inflammation in mice
}

\author{
LG Bankova ${ }^{1}$, DF Dwyer ${ }^{1}$, AY Liu ${ }^{2}$, KF Austen ${ }^{1}$ and MF Gurish ${ }^{1}$
}

In contrast to resident constitutive mast cells (CMCs), mucosal MCs (MMCs) appear in the lung and trachea of sensitized mice only following inhalation challenge. We monitored the influx and maturation of MCs by their expression of Kit, FcERI, $\beta$ 7-integrin and side scatter (SSC) by flow cytometry. Influx of MC progenitors (MCps) (Fc\&RI ${ }^{\text {lo }}, \mathrm{Kit}^{\text {int }}, \boldsymbol{\beta} 7^{\text {hi }}$, and $\mathrm{SSC}^{\circ}$ ) peaks 1 day after challenges and subsides to baseline by day 7 after challenge. The mature MMCs appear as a distinct population on day 7 and peak at day 14 with higher SSC and Fc\&RI expression, but lower $\beta 7$ and Kit expression. A distinct transitional population is present between 1 and 7 days after challenge. Maturation occurs more rapidly in the trachea. The resident tracheal CMCs had higher SSC, Fc\&RI, and Kit and lower $\beta 7$-integrin expression than the MMCs. By histology, the MMCs follow similar kinetics to the flow cytometry-identified mature MMCs and are notably persistent for $>42$ days. Steroid treatment reduced inflammation and MCp influx but had no effect on established MMCs. Thus, changes in SSC, Fc\&RI, and Kit together with the expression of $\alpha \mathrm{E} / \alpha 4: \beta 7$-integrins characterizes the development of induced MMCs from MCps and distinguishes them from resident CMCs in the trachea and large airways.

\section{INTRODUCTION}

Mast cells (MCs) are classically defined as granulated cells of hematopoietic origin that reside at the portals of pathogen or allergen entry and are best known for their ability to release quickly a number of mediators via secretion and degranulation upon activation. ${ }^{1-3}$ Classically, mature MCs have been divided into two subclasses based on their anatomic location, staining characteristics, radiation sensitivity, and T-cell dependence for development. ${ }^{4-8}$ The dominant MC population in naive mice, designated as constitutive MCs (CMCs) herein, are innate immunocytes that often reside in the connective tissue near blood vessels and nerves, are extensively granulated, and are unaffected by T-cell deficiency. ${ }^{6-8}$ In mice, they appear to arise from progenitors in the liver during fetal development. ${ }^{9}$ Mucosal mast cells (MMCs) arise from the bone marrow (BM), are induced by T-cell-dependent inflammation in organs such as the intestine and airways, have a dominant intraepithelial location, and are absent in mice and humans with inborn or acquired T-cell deficiencies. ${ }^{7,8,10-13}$
MCs are generally very low or absent in the peripheral blood. ${ }^{11-13}$ The agranular or poorly granulated MC progenitors (MCps) reside in the BM and spleen of naive adult mice. In helminth-infected mice, they increase in number at these sites and also appear in draining lymph nodes. ${ }^{14-17}$ Phenotypically, both tissue-resident MCs and MCps are characterized by the surface expression of the receptor tyrosine kinase (Kit) for stem cell factor as this pairing is required for their viability and tissue distribution and by expression of the high affinity receptor for IgE, FceRI. ${ }^{16-19}$ Expression of $\alpha 4 \beta 7$-integrin by MCps was implicated by its requirement for their transendothelial migration from blood to peripheral tissues and this was confirmed by flow cytometry (fluorescence-activated cell sorter (FACS)) analysis of the BM and spleen. ${ }^{17,20,21}$ Once in the target organs, MCps were thought to serve one major function-conversion to mature granulated MCs of the mucosal phenotype by an underlying inflammatory process.

Because of their constitutive presence, CMCs are major players in the IgE-mediated anaphylactic response of humans

\footnotetext{
${ }^{1}$ Division of Rheumatology, Immunology and Allergy, Brigham and Women's Hospital and Department of Medicine, Harvard Medical School, Boston, Massachusetts, USA and ${ }^{2}$ Division of Immunology and Allergy, Department of Pediatrics, Stanford University School of Medicine, Palo Alto, California, USA. Correspondence: MF Gurish (mgurish@partners.org)
}

Received 21 May 2014; accepted 4 September 2014; published online 8 October 2014. doi:10.1038/mi.2014.91 
and animals, including mice.22 However, in humans with bronchial asthma, both intraepithelial and intramuscular MCs have been implicated in determining the degree of airways hyperresponsiveness. ${ }^{23,24}$ In mouse models of ovalbumin-induced T helper type 2 (Th2) airway inflammation, the induced MMCs are believed to contribute to the aggregate inflammation resulting in remodeling and secondary airway hyperreactivity. ${ }^{25-27}$ Given the histologic evidence that induced MMCs are inflammation dependent and transient, while resident sentinel CMCs are stable in numbers, it seemed pertinent to develop real-time assays of their membrane phenotypes to follow the appearance, maturation, and disappearance of MMCs during a Th2 inflammatory response.

We find that the influx of MCps into the lung, as defined by the level of expression of cell surface Fc\&RI, Kit, and $\beta 7$-integrin with a minimal side scatter (SSC) profile, peaks early after allergen challenge in sensitized mice. This is followed by the appearance of two discrete subsets that characterize their phenotypic progression to an intermediate stage and then to the ultimate mature MMCs over 14 days. This progression is accelerated in the trachea where there are few MCps. The changes in level of expression of Kit, FceRI, the $\alpha 4, \alpha \mathrm{E}$, and $\beta 7$ integrins, and the SSC profile that occur with the maturation of MMCs are striking in contrast to their highly stable expression by the resident CMCs over the time course of 14 days after challenges. With full maturation as MMCs, all of those expressing $\beta 7$ integrin also are positive for $\alpha \mathrm{E}$. Once induced, the duration of MMCs in the airways, evaluated by histology, is substantial, lasting at least a month after elimination of antigen (Ag) exposure for the large airways and somewhat longer for the trachea. However, the progressive decline in Kit expression with the maturation of MMCs, as compared with its stable high presence in CMCs seen by FACS, may contribute to their differing lifespans in the airways.

\section{RESULTS}

Recruitment of MCps and appearance of induced MCs in the lung after seven aerosolized OVA challenges of sensitized BALB/c mice

To investigate the influx of MCps and their maturation in real time in the lungs of sensitized and aerosolized Ag-challenged mice, we analyzed the $\mathrm{CD} 45^{+}$, non- $\mathrm{B}$, non- $\mathrm{T}$ cells for expression of Kit (CD117) and FceRI. We used a mixture of anti-FceRI and anti-IgE antibodies to detect occupied and unoccupied FceRI on MCs because bound IgE can interfere with detection of FcERI $\alpha$ by the MAR1 monoclonal Ab (mAb). ${ }^{17}$ Compared with sensitized, nonchallenged (NC) mice, the number of leukocytes harvested from the lungs (the inflammatory cell infiltrate) increases significantly to a peak at D1 after challenge and declines to baseline levels by D14 (Figure 1a). At the same time, the increase in the concentration of MCs per $10^{6} \mathrm{CD} 45^{+}$ cells, peaks at D1 and persists on a plateau to D14 even though the inflammatory cell infiltrate, measured as number of leukocytes harvested, has returned to baseline.

There are distinct differences in the level of expression of both FceRI and Kit within the population of lung MCs at the various time points after challenge, which allows us to distinguish three populations of MCs (Figure 1b). As the three populations are most distinct at $\mathrm{D} 7$, we use this time point to set the gates to follow these phenotypes in NC mice and in mice at D1 to D14. They are designated (and colored) as FceRI ${ }^{\text {lo }} \mathrm{Kit}^{\text {int }}$ (green), Fc\&RI ${ }^{\text {int }} \mathrm{Kit}^{\text {int }}$ (red), and $\mathrm{Fc}_{\mathrm{R}} \mathrm{RI}^{\mathrm{int}} \mathrm{Kit}^{\text {lo }}$ (blue). The population of Fc\&RI ${ }^{\text {lo }} \mathrm{Kit}^{\text {int }}$ cells in NC mice are likely immature MCps as this population is expanded at D1 after challenge (Figure 1b, c, green dots and bars). These MCps peak at D1 and then decline sharply to baseline by D7 consistent with our previous indirect measurements of MCps using the limiting dilution with clonal expansion assay. ${ }^{20,28}$ The population of

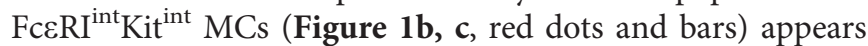
prominently first on D1 and plateaus on D7 as compared with a negligible presence in the NC mice, implying that this is an early induced population of MCs. At D7, the population of $\mathrm{FcERI}^{\text {int }} \mathrm{Kit}^{\text {lo }}$ cells appears prominently for the first time (Figure 1b, c, blue dots and bars). This latter FcERI ${ }^{\text {int }} \mathrm{Kit}^{\text {lo }}$ population peaks at D14, while the FceRI ${ }^{\text {int }} \mathrm{Kit}^{\text {int }}$ population declines, suggesting a maturation relationship. The sequence for these three populations appearing, peaking, and resolving at the different time points after challenge implies a sequential relationship from the $\mathrm{Fc}_{\mathrm{R}} \mathrm{RI}^{\mathrm{lo}} \mathrm{Kit}^{\mathrm{int}} \mathrm{MCps}$ to early induced ${ }_{\mathrm{F}} \varepsilon \mathrm{RI}^{\mathrm{int}} \mathrm{Kit}^{\text {int }} \mathrm{MMCs}$ (eMMCs) to mature $\mathrm{Fc}_{c} \mathrm{RI}^{\text {int }} \mathrm{Kit}^{\text {lo }} \mathrm{MMCs}$. As the only induced MCs seen in mouse lung by histology with allergic inflammation are intraepithelial MMCs, we use these designations for simplicity.

\section{MCps and induced lung MCs also differ in their SSC by FACS and $\beta 7$ integrin expression}

To further characterize these three populations of recruited and induced MCs, we assessed their expression of $\beta 7$ integrins implicated in the transendothelial recruitment of MCps to mouse lung, ${ }^{20,21}$ and also analyzed their size and granularity characteristics by their forward scatter (FSC) and SSC profiles. The population of MCps at D1 in challenged mice has the highest expression level of $\beta 7$ integrin as depicted for a representative result (Figure 2a, green histogram) and by the mean net MFI (mean fluorescence intensity) (green bar, bottom panel). The $\beta 7$ integrin surface expression on these MCps found at D1 does not change as their numbers fall at later time points (data not shown). The eMMCs have lower $\beta 7$ integrin expression compared with the MCps on D1 (Figure 2a, red vs. green line and bars). The population of MMCs has a similarly lower expression of $\beta 7$ integrin at D7 (Figure 2a, blue line and bar), indicating a decline of $\beta 7$ integrin expression with maturation. The level of $\beta 1$ integrin expression on the cells at the three stages of development is similar with a small but statistically significant difference in net MFI between MCps and the more mature MCs (Figure 2b). Comparison for granularity using SSC reveals that on D7, the MCps are the least granular and comparable to splenic MCps (Figure 2c, green line vs. gray shaded area). The eMMCs are intermediate for SSC and the MMCs have the highest SSC (Figure 2c, red and blue lines) compatible with further maturation. Comparison of the three populations for FSC characteristics shows no differences (Figure 2d). 

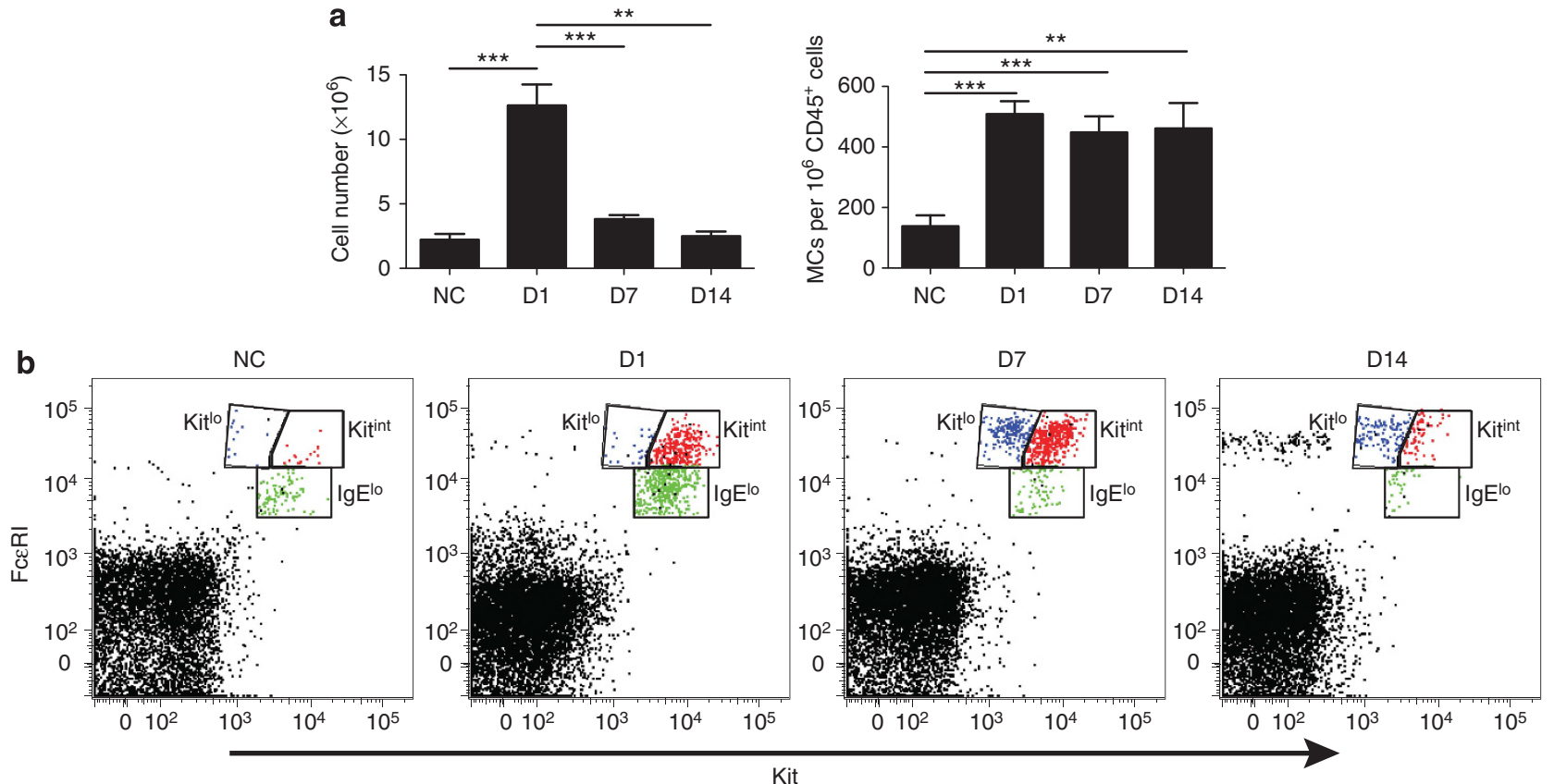

C
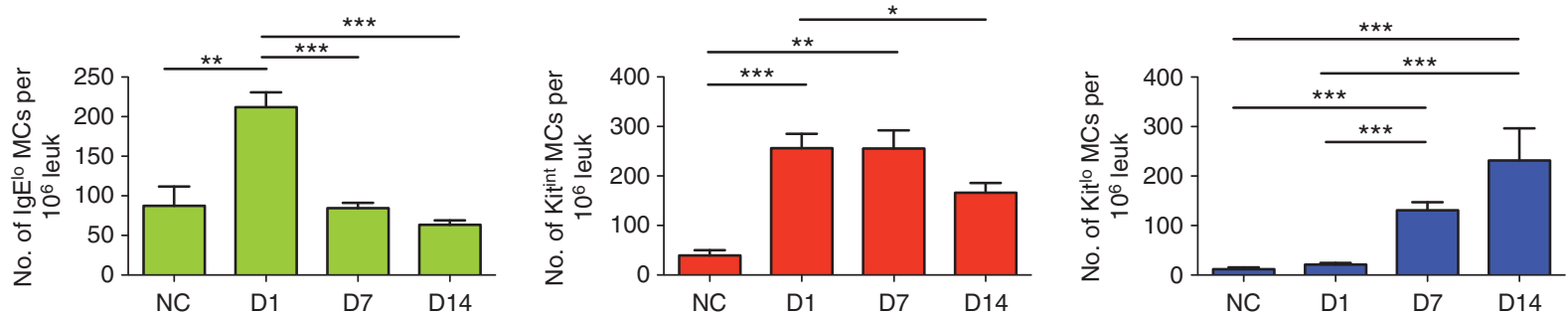

Figure 1 Induction of three populations of mast cells (MCs) in the lung of BALB/c mice 1 to 14 days after challenges. BALB/c mice were sensitized and either not challenged (NC) or challenged for 7 consecutive days with aerosolized antigen. The lung cells were isolated and analyzed by flow cytometry on day (D)1, D7, and D14 after the challenges. (a) Mean leukocyte (leuk) cell counts (left panel) and mean number of Fc\&RI ${ }^{+} \mathrm{Kit}^{+} \mathrm{MCs}$ per $10^{6}$ $\mathrm{CD} 45^{+} \mathrm{CD} 3^{-} \mathrm{CD} 19^{-} \mathrm{CD} 11 \mathrm{~b}^{-}$cells in the lung (right panel). (b) Representative dot plots of MCs from NC and challenged mice analyzed for FceRI and

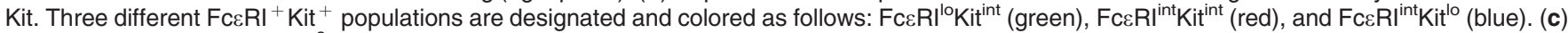
Concentration (number per $10^{6} \mathrm{CD} 45^{+}$leukocytes) of lung MC lineage populations (Fc\&RI ${ }^{+} \mathrm{Kit}^{+}$) colored as in b. Bar graphs represent means \pm s.e.m.'s from five experiments with 7-15 mice per group. ${ }^{\star} P<0.05,{ }^{* \star} P<0.01$, and ${ }^{\star * \star} P<0.001$.

As both $\alpha 4 \beta 1$ and $\alpha 4 \beta 7$ integrins are important in the transendothelial migration of MCps into inflamed lung, ${ }^{20}$ we evaluated each population for the expression of the $\alpha 4$ integrin chain (CD49d) and for the expression of the $\alpha \mathrm{E}$ integrin chain (CD103), the alternate $\alpha$ chain that pairs with the $\beta 7$ integrin chain. The comparison of the expression of $\alpha 4$ on the MCps on D1 with the eMMCs and the MMCs on D7 indicates that the number of $\alpha 4$ integrin $^{+}$cells decreases as the cells mature (Figure 3a, b). There is a decrease in the relative percentage of $\alpha 4^{+}$cells from $66 \%$ of MCps on D1 to $50 \%$ of eMMCs on D7 to $20 \%$ of MMCs on D7 (Figure 3b). Furthermore, whereas $\beta 1$ expression does not change with maturation (Figure 3a, b), $\beta 7^{+}$cells decline from $95 \%$ of MCps on D1 to $72 \%$ of eMMCs and to $61 \%$ of MMCs on D7 (Figure 3c, d). The $\alpha \mathrm{E}$ integrin ${ }^{+}$cells decrease modestly from $63 \%$ of MCps on D1 to $26 \%$ of eMMCs and $53 \%$ of MMCs on D7 (Figure 3c, d). Thus, as the induced MMCs mature from MCps, some lose their $\alpha 4$ integrin chain and a lesser number their $\beta 7$ integrin subunit. When they reach their final stage of maturation, the MMCs expressing $\beta 7$ integrins are predominantly $\alpha \mathrm{E} \beta 7^{+}$.

To distinguish the contribution of $\alpha 4$ and $\alpha \mathrm{E}$ integrins to the recruitment of MCps, we used mAbs directed to the $\alpha$-chain components of the heterodimers, $\alpha 4$ and $\alpha \mathrm{E}$. We found a significant $79 \%$ reduction in the concentration of MCps per $10^{6}$ $\mathrm{CD} 45^{+}$leukocytes and a $27 \%$ reduction in the concentration of eMMCs per $10^{6} \mathrm{CD} 45^{+}$leukocytes $(P=0.07)$ in mice treated with $\alpha 4$ antibody compared with isotype-treated mice $(n=3$ mice per group in a single experiment). Mice given $\alpha \mathrm{E}$ antibody showed no reduction in MCp recruitment.

\section{Comparison of constitutive and induced populations of MCs in the trachea with allergic inflammation}

Our prior histologic analyses had revealed that in the trachea, submucosal CMCs were abundant and comparable in numbers in sensitized, NC, and Ag-challenged mice, while MMCs were absent in sensitized NC mice and only appeared in the trachea with Ag challenge. ${ }^{28}$ We used this knowledge to compare these 
a
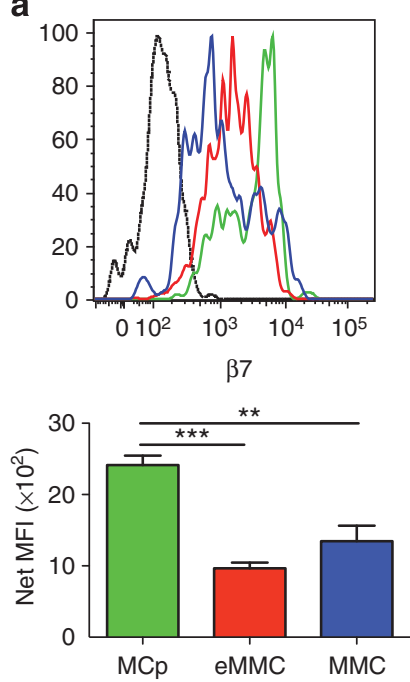

C

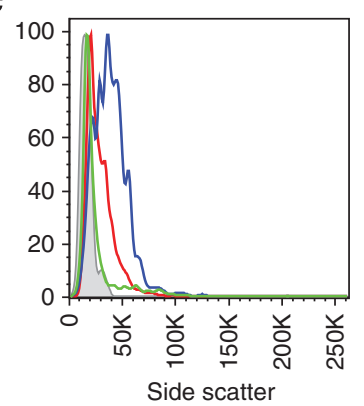

b
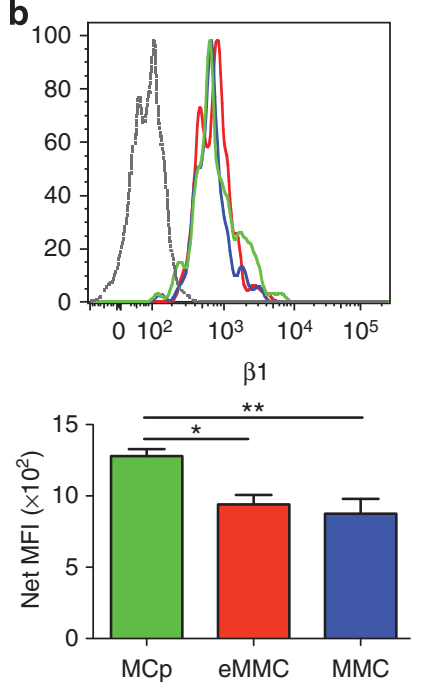

d

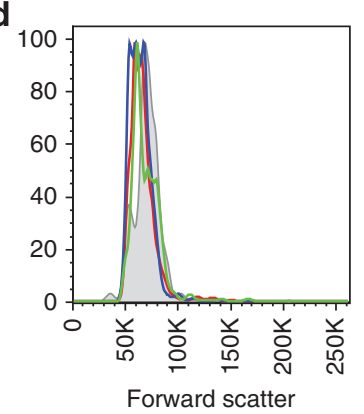

Figure 2 Expression of $\beta 7$ and $\beta 1$ integrins and forward and side scatter characteristics of inducible lung mast cell (MC) populations at D7 after challenges. (a) Representative histograms (top panel) and mean ( \pm s.e.m.) net MFI (mean fluorescence intensity) (bottom panel) of $\beta 7$ integrin expression by the three populations of lung MCs: MC progenitors (MCps) (green), early induced Fc\&RI ${ }^{\text {int }}$ Kit ${ }^{\text {int }}$ MMCs (eMMCs) (red), and mucosal MCs (MMCs) (blue); isotype control (black dotted line). Net MFI was determined by subtracting the value of the isotype control. (b) Representative histograms (top panel) and mean ( \pm s.e.m.) net MFI (bottom panel) of $\beta 1$ (CD29) integrin expression by the three populations of lung MCs (top panel) colored as in a. (c) Representative histograms show the side scatter profile of the three lung MC populations colored as in $\mathbf{a}$. Gray shaded area indicates immature spleen MCps. (d) Representative histograms show the forward scatter profile of the three lung MC populations compared with spleen MCps as in c. Histograms in $\mathbf{c}$ and d show the mean value from 2-3 mice per group from one of five experiments. Bar graphs present means \pm s.e.m.'s from three to five separate experiments with 5-13 mice per group.

subclasses of MCs in the same airway for their expression of Fc\&RI, Kit, and $\beta 7$ integrin and for their SSC profile. Mature CMCs in mouse lung are limited to the large bronchi and subpleural space, ${ }^{28,29}$ and thus are rare in the lung cell preparations.

In our FACS analysis of trachea, the population of MCps that increases in the lung on D1 is not recognized (Figure 4a). Instead, a population of $\mathrm{Fc}_{\mathrm{C}} \mathrm{RI}^{\mathrm{int}} \mathrm{Kit}^{\text {int }}$ MCs that is poorly demarcated in the trachea of NC mice is increased on D1 but not D7, and is similar to the transient population of eMMCs in the lung (Figure $\mathbf{4 a}, \mathbf{b}$, red dots and bars). Further, a

FceR $I^{\text {int }} \mathrm{Kit}^{\text {lo }}$ population of MMCs is also distinct on D1 in the trachea and peaks in numbers on D7 with little change to D14 (Figure 4a, b, blue dots and bars). The kinetics of induction of the mature MMC phenotype in trachea appears to be much accelerated compared with the lung. The trachea also contains Fc\&RI ${ }^{\text {hi }} \mathrm{Kit}^{\mathrm{hi}} \mathrm{MCs}$ that are present before challenge and do not increase in number with the inflammatory response to challenge (Figure 4, orange dots and bars), indicating the constitutive MC phenotype. At D7-14, the MMCs are $>10$ fold greater per $10^{5} \mathrm{CD} 45^{+}$leukocytes than the CMCs.

The eMMCs transiently present on D1 in the trachea have the highest $\beta 7$ integrin expression of MCs in the trachea (Figure 5a, red line and bar). The mature MMCs have less $\beta 7$ integrin expression (Figure 5a, blue line and bar) than eMMCs, while their $\beta 1$ expression is similar (Figure $5 \mathbf{b}$ ). The granularity by SSC is greater in MMCs than in the eMMCs, which is greater than splenic MCps (Figure 5c, blue line, red line, and gray shaded area, respectively). Nonetheless, the SSC of MMCs is still lower than that of the tracheal Fc\&RI ${ }^{\text {hi }} \mathrm{Kit}^{\text {hi }} \mathrm{CMCs}$, which is modest compared with peritoneal MCs (Figure $\mathbf{5 c}$, orange line and black dotted line, respectively). The FSC of CMCs is lower than that of the inducible trachea eMMC and MMC populations, with the eMMCs being comparable to peritoneal MCs (Figure 5d).

Assessment of the different $\alpha$-chain partners of the $\beta 7$ integrin shows that the eMMCs are 59\% positive for $\alpha 4$ on D1 and that this decreases to $4 \%$ on the MMCs on D7 (Figure 6a, b). In contrast, the expression of $\alpha \mathrm{E}$ is retained at $59 \%$ of eMMCs and $66 \%$ of MMCs (Figure 6 c, d). There is no change in expression of $\beta 1$ integrin, while the $\beta 7$ integrin expression is decreased from $92 \%$ of eMMCs to $68 \%$ of MMCs. The majority of MMCs on D7 are positive for both $\alpha \mathrm{E}$ and $\beta 7$ integrin chains. Most of the CMCs in the trachea express $\beta 1$ integrin and about one-half are positive for $\beta 7$, while only about one-third express $\alpha 4$ and very few are positive for the $\alpha \mathrm{E}$ integrin chains (data not shown).

\section{Persistence of airway MMC numbers}

Because our analyses by FACS and prior studies of lung and trachea by histology ${ }^{28}$ had shown induction of MMCs by D1 but had not addressed their duration, we evaluated the time course for induction and resolution of challenge-induced MMCs in the lung and trachea by histology. Intraepithelial MMCs in the trachea are significantly increased on D1 and their numbers increase further to a plateau from D7 to D21 consistent with the analysis by FACS (Figure 7a). Although, there is a gradual decrease in MMC numbers thereafter, the numbers at D42 and D77 are still greater than for the NC controls. The number of tracheal CMCs does not change over the 77 days (Figure $7 \mathbf{b}$ ), consistent with previous results for D1-7. ${ }^{28}$ Histologic analysis also demonstrates a distinct phenotype for tracheal MMC characterized by larger granules and smaller sized cells relative to the tracheal CMC (Supplementary Figure 1 online). This phenotypic difference between the major classes of MCs has been described in the mouse small intestine. $^{10}$ 
a
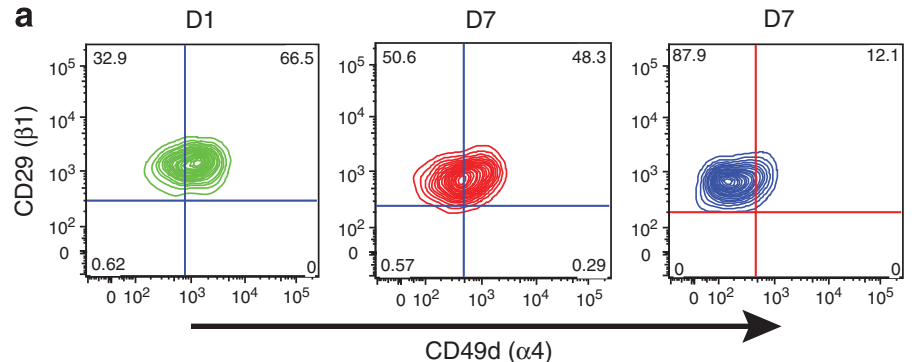

C

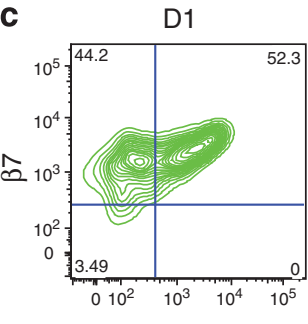

CD49d ( $\alpha 4)$

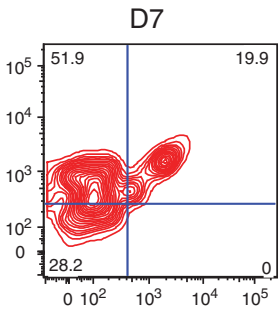

D7

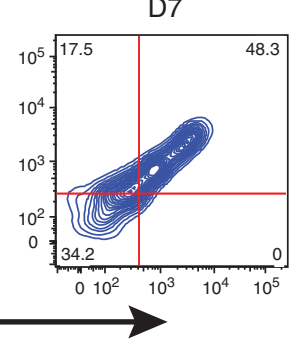

b

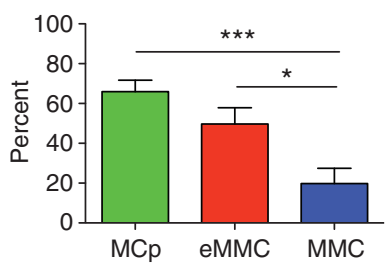

d

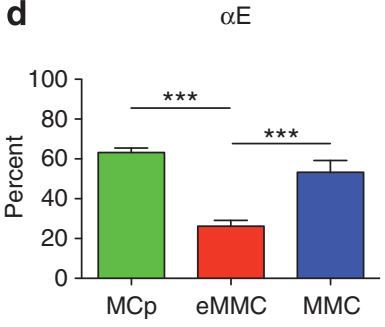

$\beta 1$
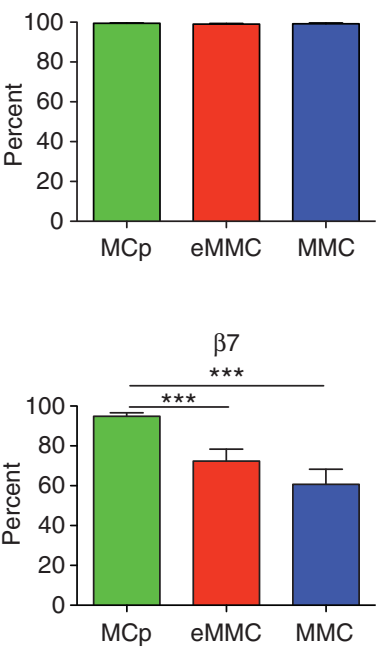

Figure 3 Expression of $\alpha 4, \alpha \mathrm{E}, \beta 7$, and $\beta 1$ integrins on the inducible mast cell (MC) populations in the lung. (a) Representative contour plots presenting the expression of $\alpha 4$ and $\beta 1$ integrins on MC progenitors (MCps) (green) on day (D) 1, early induced Fc\&RI ${ }^{\text {int } K t^{\text {int }}}$ MMCs (eMMCs) (red) on D7, and mucosal MCs (MMCs) (blue) on D7. (b) Mean \pm s.e.m. percentage of cells positive for $\alpha 4$ and $\beta 1$ integrins in each of the three MC populations colored as in a. (c) Representative contour plots presenting the expression of $\alpha \mathrm{E}$ and $\beta 7$ on the MCp, eMMC, and MMC as in a. (d) Mean \pm s.e.m. percentage of cells positive for $\alpha E$ and $\beta 7$ integrins in each of the three $M C$ populations colored as in $\mathbf{a}$. Data in $\mathbf{b}$ and $\mathbf{d}$ are from four experiments with 8-12 mice per group. ${ }^{*} P<0.05$ and ${ }^{* * *} P<0.001$.

a

NC

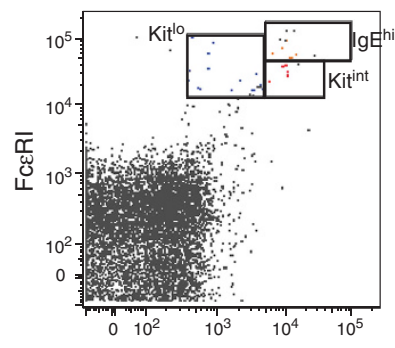

D1

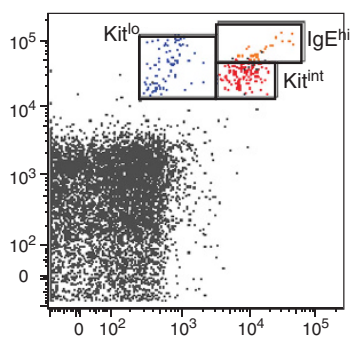

D7

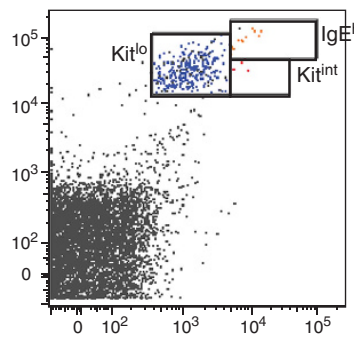

D14

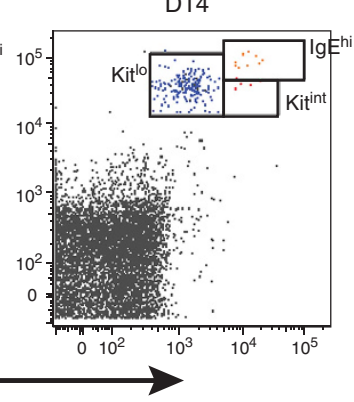

b
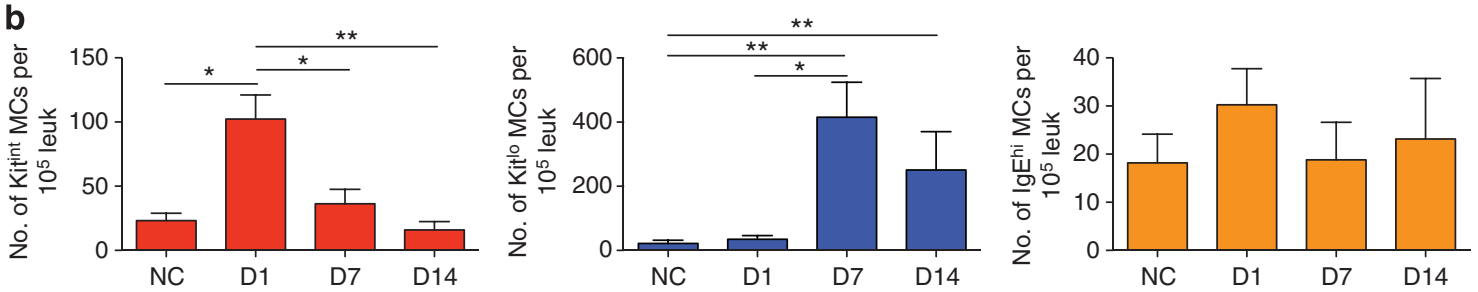

Figure 4 Induction of two populations of mast cells (MCs) in the trachea of BALB/c mice 1-14 days after challenges. (a) Representative dot plots of

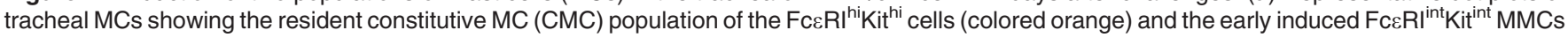
(eMMCs) (red) and mucosal MCs (MMCs) (blue) populations in nonchallenged (NC) mice and in mice day (D)1, D7, and D14 after challenges from one of three experiments. (b) Mean \pm s.e.m. concentration (MCs per $10^{5} \mathrm{CD} 45^{+}$leukocytes) of CMCs, eMMCs, and MMCs colored as in a. Data are means \pm s.e.m.'s from five experiments with 6-15 mice per group. ${ }^{*} P<0.05$ and ${ }^{* *} P<0.01$.

In the lung, a few MMCs are detectable in the large bronchi on D1 and their numbers are significantly increased to a plateau on D7-21 (Figure 7c). These bronchial MMCs decline in numbers by D42 and are almost back to baseline absence at D77. In the lung, CMCs are only occasionally found in the subpleural space and in the connective tissue surrounding the right and left main stem bronchus. $^{28,29}$ 
a

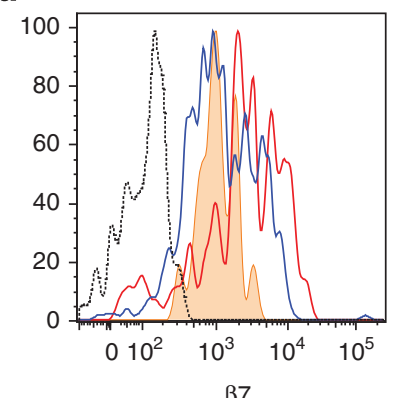

b
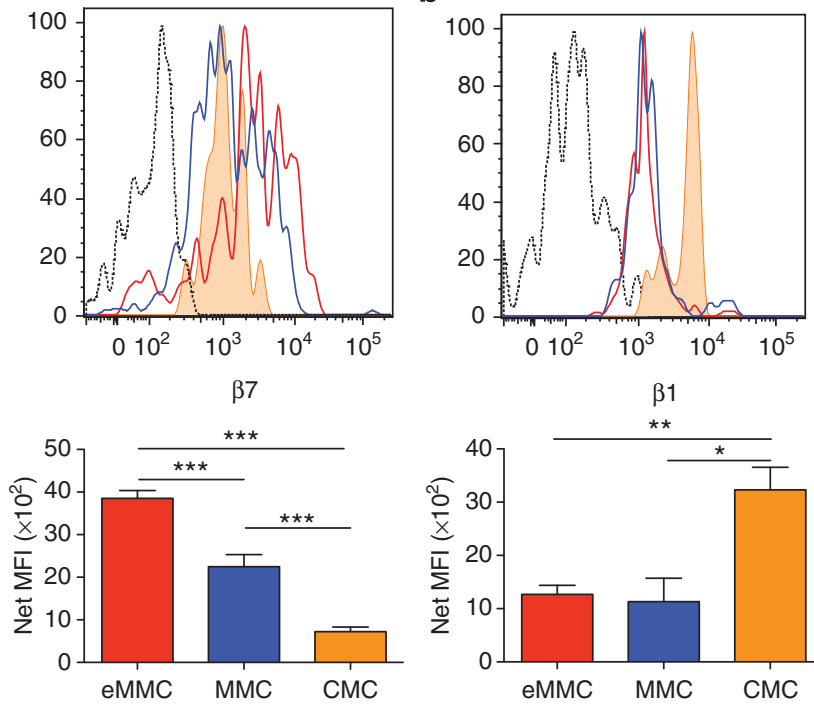

c

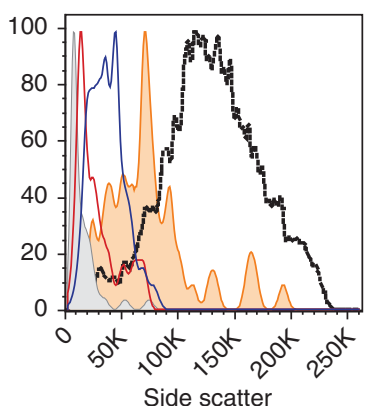

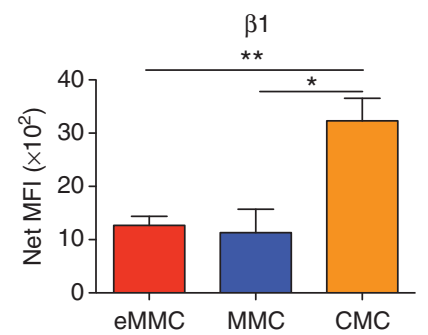

d

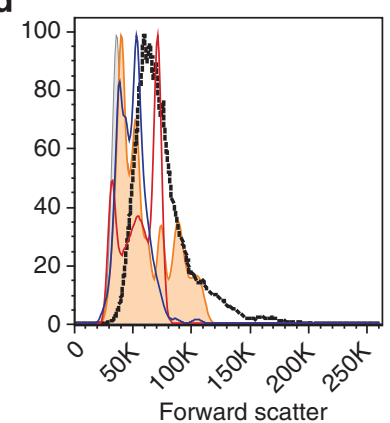

Figure 5 Expression of $\beta 7$ and $\beta 1$ integrins and forward and side scatter characteristics of tracheal constitutive and inducible MC populations at day (D)7 after challenges. (a) Representative histograms (top panel) and mean ( \pm s.e.m.) net MFI (mean fluorescence intensity) (bottom panel) of the $\beta 7$ integrin expression on the three populations of tracheal MCs, constitutive mast cell (CMCs) (orange shaded), early induced Fc\&RI ${ }^{\text {int }}$ Kit $^{\text {int }}$ MMCs (eMMCs) (red), and mucosal MCs (MMCs) (blue); black dotted line-isotype control. (b) Representative histograms (top panel) and mean ( \pm s.e.m.) net MFI (bottom panel) of the $\beta 1$ (CD29) integrin expression on the three populations of tracheal MCs colored as in a. (c) Representative histograms of the side scatter characteristics of the three MC populations in trachea (colored as in a and compared with splenic MC progenitors (MCps) (gray shaded) and intraperitoneal MCs (back dotted line). (d) Forward scatter characteristics of tracheal, splenic, and intraperitoneal $\mathrm{MC}$ populations as in $\mathbf{c}$. Histograms in $\mathbf{c}$ and $\mathbf{d}$ show the mean value from 2 to 3 mice per group from one of five experiments. Bar graphs represent mean ( \pm s.e.m.) from four experiments with 5-8 mice per group. ${ }^{*} P<0.05$, ${ }^{\star *} P<0.01$, and ${ }^{\star * \star} P<0.001$.

\section{Effect of systemic steroids on the recruitment to and persistence of MCs in the lung and trachea}

The persistence of Ag-induced lung MCs prompted an investigation of the effect of treatment with systemic steroids on the recruitment of MCps and their transition to eMMCs and on the survival of established eMMCs and MMCs using two different protocols. To examine the effect of steroid treatment on MCp recruitment, sensitized mice received prednisone or Hank's balanced salt solution (HBSS) intraperitoneally (i.p.) every other day during the aerosol challenge phase with analysis

1 day after the last challenge, D1. The numbers of MCps (FcERI ${ }^{\text {lo }} \mathrm{Kit}^{\text {int }}$ ) per lung along with the inflammatory response defined by numbers of leukocytes harvested from lungs are significantly decreased in challenge-phase steroid-treated mice (Figure 8). The numbers of developed eMMCs are also much reduced, although significance is not reached $(P=0.065)$. The concentration of MCps and eMMCs (per $10^{6} \mathrm{CD}^{6} 5^{+}$cells) in the lung increases with challenge of sensitized mice and this response is not reduced by treatment with steroids (Figure $\mathbf{8 b}$ ). Thus, although their numbers per lung are diminished by steroid treatment (Figure 8c), neither the MCps nor the eMMCs are selectively depleted relative to other leukocytes. In the trachea, the eMMCs (FceRI ${ }^{\text {int }} \mathrm{Kit}^{\text {int }}$ ) appearing at D1 are not reduced in number or in concentration per CD45 ${ }^{+}$leukocytes by steroid treatment (data not shown).

To examine the effect of steroid treatment on established eMMCs and MMCs, sensitized and challenged mice were treated with prednisone beginning 1 day after the last challenge, D1, and every other day until analysis on D7. By D7 the inflammatory infiltrate is essentially dissipated and the additional reduction in the lung leukocytes with steroid administration is not significant (Figure 9a). Neither the numbers per lung nor the concentration (per $10^{6} \mathrm{CD} 45^{+}$cells) of eMMCs alone, or plus MMCs, are reduced by steroid treatment as compared with the HBSS-treated mice (Figure 9b, c). Similarly, in the trachea the postchallenge administration of corticosteroids has no effect on the numbers or concentration of eMMCs and MMCs (data not shown).

\section{DISCUSSION}

In this study, we have followed the recruitment and maturation of lineage MCs in the lung and trachea by FACS analysis during Ag-induced pulmonary inflammation in $\mathrm{BALB} / \mathrm{c}$ mice. We used four distinct markers to visualize the recruitment of the MCps and then their maturation through an intermediate stage, eMMCs, to the fully mature MMCs. In trachea, we also differentiated the induced MMCs from the resident CMCs. We had previously required separate cohorts of mice to monitor recruitment of MCps to tissue by limiting dilution and clonal expansion $^{20,30}$ and, in parallel, documented the appearance of mature interepithelial MMCs in the presence of CMCs in large airways by histologic criteria in large airways. ${ }^{28,31} \mathrm{We}$ had indirect evidence of recruitment as opposed to expansion of the endogenous tissue MCps because their appearance after Ag challenge was blocked by the administration of mAb to $\alpha 4 \beta 1$ and $\alpha 4 \beta 7$ integrins or to the endothelial counter-ligand, vascular cellular adhesion molecule-1. ${ }^{20}$ These ex vivo enumerated MCps peaked in number 1 day after seven challenges and fell off substantially by D4 after challenges, whereas the induced MMCs, assessed by histology, began appearing in the lung and trachea on D1 and were increased at D4. ${ }^{28}$ We have now visualized this process in real time by FACS analysis of dissociated lung and tracheal cells from unchallenged and challenged, sensitized mice from D1 to D14 after seven challenges, and extended our observations by histology out to D77. 
a

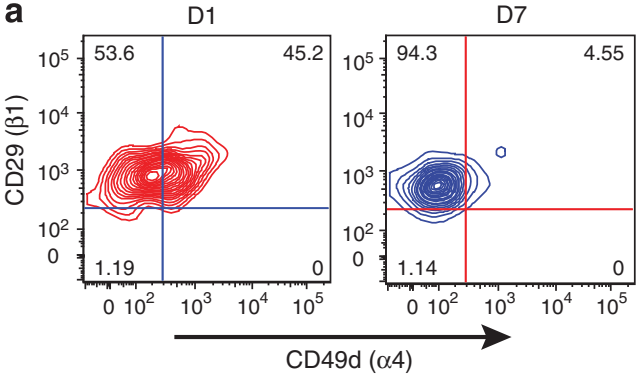

C

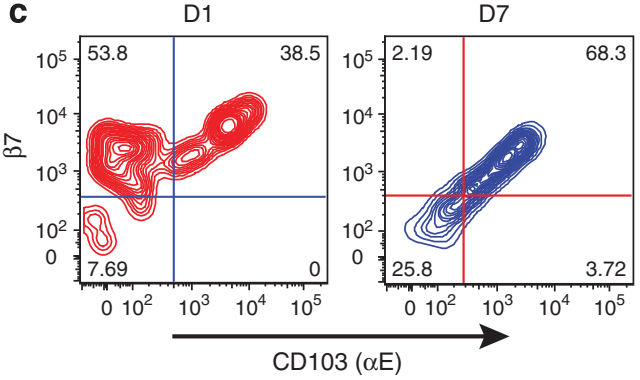

b

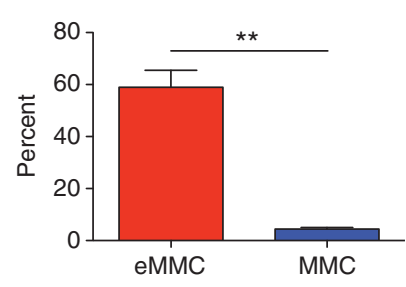

d

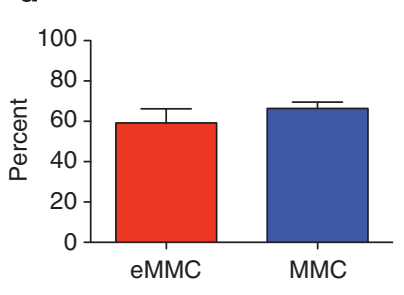

$\beta 1$
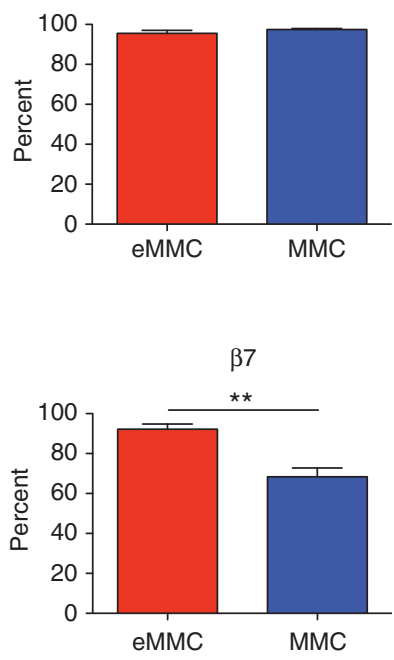

Figure 6 Expression of $\alpha 4, \alpha \mathrm{E}, \beta 7$, and $\beta 1$ integrins on the constitutive and inducible mast cell (MC) populations in the trachea. (a) Representative contour plots presenting the expression of $\alpha 4$ and $\beta 1$ integrins on early induced Fc\&RI ${ }^{\text {int }}$ Kit $^{\text {int }}$ MMCs (eMMCs) (red) on day (D)1, and mucosal MCs (MMCs) (blue) on D7 after challenges. (b) Mean ( \pm s.e.m.) percentage of cells positive for $\alpha 4$ and $\beta 1$ integrins in the two MC populations, D1 eMMCs, and D7 MMCs as in a. (c) Representative contour plots presenting the expression of $\alpha E$ and $\beta 7$ integrins colored as in a. (d) Mean ( \pm s.e.m.) percentage of cells positive for $\alpha \mathrm{E}$ and $\beta 7$ integrins in the two MC populations colored as in a. Data are means \pm s.e.m.'s from from four experiments with $4-8$ mice per group. ${ }^{* *} P<0.001$.
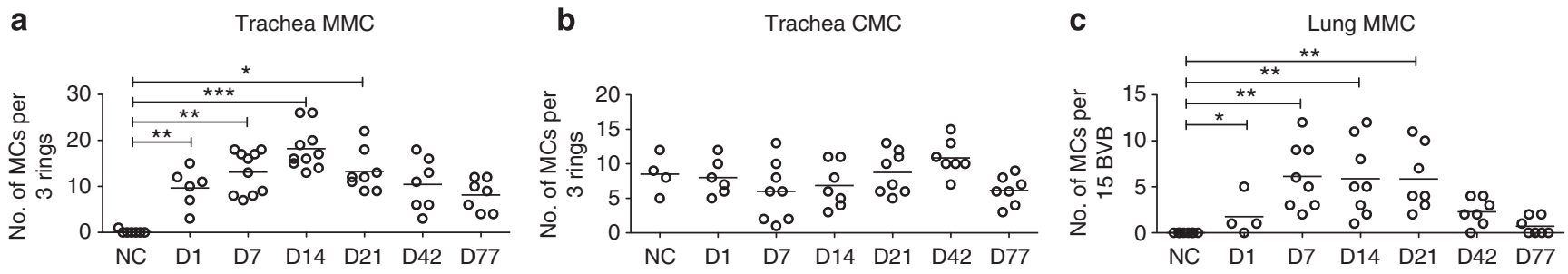

Figure 7 Persistence of histologic mucosal MC (MMC) hyperplasia in the lung and trachea. Time course showing the changes in the numbers of MMCs and constitutive MCs (CMCs) in the trachea and MMCs in large airways of sensitized BALB/c mice challenged up to 77 days previously or unchallenged, as assessed by histology. (a) The number of interepithelial MMCs per three tracheal rings. (b) The number of submucosal CMCs per three tracheal rings. (c) The number of interepithelial MMCs per 15 bronchovascular bundles (BVB) assessed in the large bronchi ( $>200 \mu \mathrm{m})$. Each dot is a separate mouse and the bar indicates mean value from four experiments. ${ }^{*} P<0.05,{ }^{* *} P<0.01$, and ${ }^{* *} P<0.001$.

We observe a population of FcERI ${ }^{\mathrm{lo}} \mathrm{Kit}^{\mathrm{int}} \beta 7^{\mathrm{hi}} \mathrm{SSC}^{\mathrm{lo}} \mathrm{MCps}$ in the lung of sensitized BALB/c mice that peaks in number at D1 and then returns to baseline by D7 after Ag challenge. Based on expression of FceRI and Kit and their low SSC, these recruited MCps resemble the MCps we previously observed in the spleen of naive mice and in the spleen, and lymph nodes of Trichinella spiralis-infected mice. ${ }^{17}$ At D1, there is also a population of early induced FceRI ${ }^{\text {int }} \mathrm{Kit}^{\text {int }} \beta 7^{\text {int }}$ cells, eMMCs, with slightly increased SSC that peaks in number at D7 and then decreases at D14. Finally, another distinct population of Fc\&RI ${ }^{\text {int }} \mathrm{Kit}^{\mathrm{lo}} \beta 7^{\text {int }}$ cells, mature MMCs, appears on D7 with a further increase in SSC. These MMCs peak in number in the lung on D14 with persistence to D21 (data not shown). Earlier studies have shown that an increase in Fc\&RI expression is associated with the appearance of granules in immature BM-derived MCs. ${ }^{32,33}$ Our findings for the relative shifts in the number of lineage MCs with a particular membrane phenotype and increasing granularity based on SSC implies a developmental pattern from MCp to eMMC to MMC during allergic lung inflammation. This interpretation is supported by the accompanying shift from $\alpha 4$ to $\alpha$ E integrins in association with the $\beta 7$ integrin.

The FACS analysis of the trachea was uniquely informative as this tissue has a sufficient and accessible population of CMCs that allowed comparison of induced MMCs to resident CMCs. Surprisingly, unlike the lung, a discrete $\mathrm{F}_{c} \varepsilon \mathrm{RI}^{\mathrm{lo}} \mathrm{Kit}^{\mathrm{int}} \beta 7^{\mathrm{hi}}$ population of MCps is not apparent in the trachea in unchallenged mice or even at D1 with challenge. However, similar to the lung, a population of early induced 

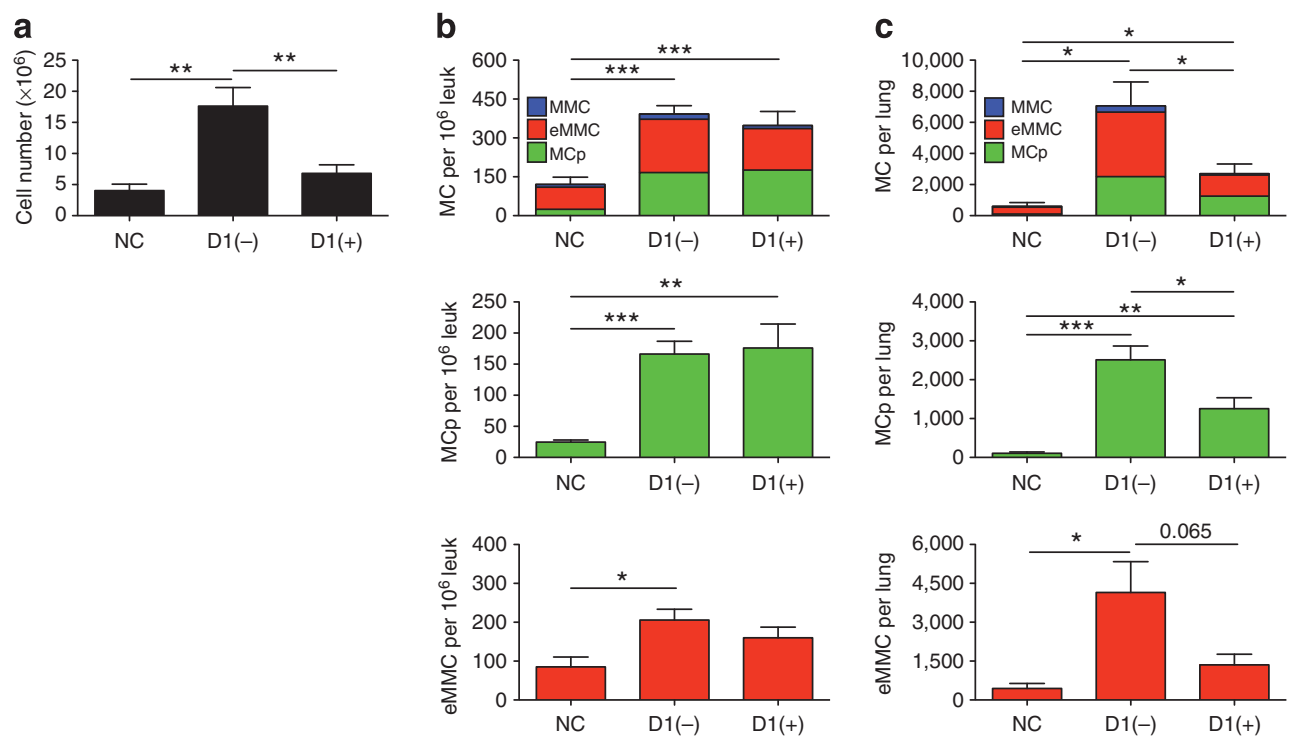

Figure 8 Effect of systemic steroids on the recruitment of MC progenitors (MCps) and appearance of early induced Fc\&RI ${ }^{\text {int }}$ Kit ${ }^{\text {int }}$ MMCs (eMMCs) in the lung of BALB/c mice. Sensitized mice were given either Hank's balanced salt solution (HBSS) $(-)$ or prednisone $(+)$ intraperitoneally every other day during the challenge phase. The CD45 ${ }^{+}$lung cells were isolated and analyzed by flow cytometry on day (D) 1 after the challenges. (a) Mean counts of leukocytes from the lung preparations. (b) Concentration of $\mathrm{Fc} \varepsilon \mathrm{RI}^{+} \mathrm{Kit}^{+} \mathrm{MCs}$ per $10^{6} \mathrm{CD} 45^{+}$cells in the lung (top panel). Stacked bars represent the concentration of all MCs and show the relative contribution of MCps (green), eMMCs (red), and mucosal MCs (MMCs) (blue) to the total number. Middle and bottom panel are bar graphs of the distinct populations that are predominant on D1, MCp (green) and eMMC (red). (c) Total number of MCs per lung in the same mice as in b. Bar graphs represent means \pm s.e.m.'s from three experiments with 9-12 mice per group. ${ }^{\star} P<0.05$ and ${ }^{\star \star} P<0.01$.
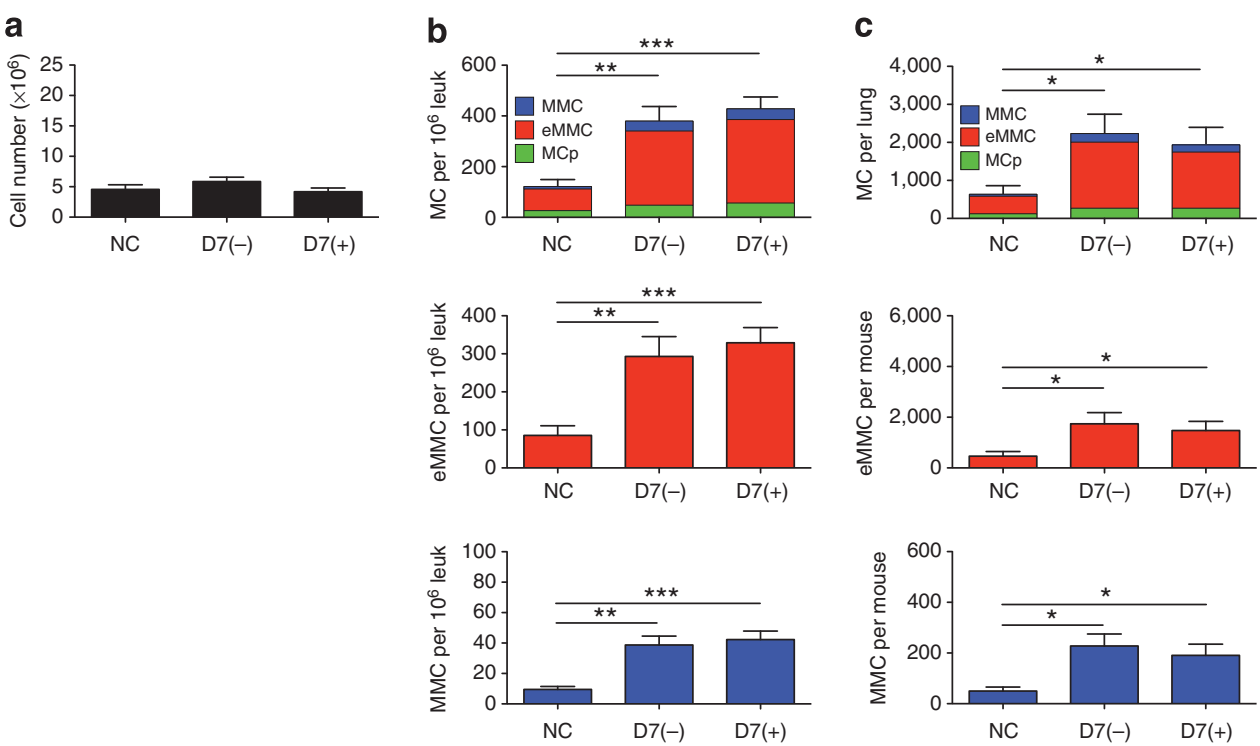

Figure 9 Effect of systemic steroids on the postchallenge presence of induced mast cells (MCs) in the lung of BALB/c mice. Sensitized and challenged mice were given four doses of Hank's balanced salt solution (HBSS) $(-)$ or prednisone $(+)$ intraperitoneally every other day (D) for 7 days after the challenge phase starting on D1 after challenge. The CD45 ${ }^{+}$lung cells were isolated and analyzed by flow cytometry on D7 after the challenges. (a) Mean cell counts of leukocytes from the lung preparations. (b) Concentration of $\mathrm{Fc \varepsilon RI}{ }^{+} \mathrm{Kit}^{+} \mathrm{MCs}$ per $10^{6} \mathrm{CD}_{4} 5^{+}$cells in the lung (top panel). Stacked bars represent the concentration of all MCs and show the relative contribution of the MC progenitors (MCps) (green), early induced Fc\&RI ${ }^{\text {int }}$ Kit $^{\text {int }} \mathrm{MMCs}{ }^{\text {in }}$ (eMMCs) (red), and mucosal MC (MMC) (blue) to the total number. Middle and bottom panels are bar graphs of the distinct populations that are predominant on D7-eMMC (red) and MMC (blue). (c) Total number of MCs per lung in the same mice as in b. Bar graphs represent means \pm s.e.m.'s from three experiments with 9 mice per group. ${ }^{*} P<0.05$.

Fc\&RI ${ }^{\text {int }} \mathrm{Kit}^{\text {int }} \beta 7^{\text {int }}$ eMMCs is apparent at D1, but is transient and does not persist to D7. Instead, only the Fc\&RI ${ }^{\text {int }} K_{i t}{ }^{\text {lo }} \beta 7^{\text {int }}$ MMCs are prominent at D7 and then persist to D14. The concentration of MMCs is 10-fold higher in the tracheal cell population than the lung. Possible explanations for an apparently faster maturation of MMCs in the trachea as 
compared with the lung include a higher relative number of fibroblasts, which promote $\mathrm{MC}$ maturation in a synovitis model $^{34}$ and which mediate maturation of BM-derived MCs in cocultures. ${ }^{35,36}$ Alternatively, a relatively higher concentration of E-cadherin in the trachea may maximize an interepithelial distribution of MCp for the development of eMMC. The resident FcERI ${ }^{\text {hi }} \mathrm{Kit}^{\mathrm{hi}} \beta 7^{\mathrm{lo}} \mathrm{CMCs}$ exhibit the highest SSC and their number does not change with inflammation, consistent with our previous observations by histologic assessment of the trachea. ${ }^{28}$ In keeping with their higher SSC, these tracheal CMCs possess more granules per cell than MMCs by histology, a finding also noted for the intestinal CMCs vs. MMCs by histology and by electron microscopy. ${ }^{10}$ Differences in granule number and electron microscopy structure also hold for human MMCs as compared with connective tissue MCs by electron microscopy. ${ }^{37,38}$

Our previous studies demonstrated that $\alpha 4 \beta 7$ and $\alpha 4 \beta 1$ integrins are critical for recruitment of MCps to the lung. ${ }^{20}$ $\mathrm{CD} 103(\alpha \mathrm{E}$ integrin) is an alternative partner for $\beta 7$, is important for the retention of lymphocytes in the epithelium through interaction with E-cadherin, and is classically induced by tumor growth factor- $\beta$ (TGF $\beta$ ). ${ }^{39-41}$ The majority of recruited MCps in the lung and induced eMMCs in the trachea are positive for both $\beta 1$ and $\beta 7$ integrins. As they mature, the inducible MCs in the lung and in the trachea downregulate their surface $\beta 7$ integrin expression and lose their $\alpha 4$ integrin expression. With full maturity as MMCs, the majority of the $\beta 7$ integrin subunits are paired with $\alpha \mathrm{E}$. There are several findings in the literature compatible with such a change during Th2-mediated inflammation. Cultured BMderived MCs stimulated with TGF $\beta$ maintain relatively stable expression of the $\beta 1$ and $\beta 7$ integrin subunits but lose their $\alpha 4$ transcript, ${ }^{42}$ and when subjected to Fc\&RI activation, upregulate the $\alpha \mathrm{E}$ integrin subunit. ${ }^{41,43}$ Furthermore, intraepithelial MCs induced in the intestine with T. spiralis infection are positive for $\alpha \mathrm{E}$ by immunofluorescence. ${ }^{44} \mathrm{TGF} \beta$ also induces a reduction in Kit expression by human skin $\mathrm{MCs},{ }^{41,45}$ and increased local TGF $\beta$ production occurs with allergic pulmonary inflammation in mouse models. ${ }^{46}$ Thus, we speculate that in response to TGF $\beta$, induced airway MMCs downregulate $\alpha 4$ and express predominantly the $\alpha \mathrm{E}$ integrin so as to bind epithelial E-cadherin, and concomitantly downregulate Kit, limiting their induced hyperplasia.

The distinct or overlapping functions of CMCs and induced MMCs are not well understood. MC-directed models of anaphylaxis or of acute bacterial resistance in naive mice reflect the functions of the resident CMCs as the MMCs are rare in naive intestine and almost undetectable in the lung. ${ }^{28,29}$ In contrast, models of allergic lung inflammation superimpose an induced MMC population on resident CMCs, and yet there is little information on the persistence of this MMC population. By FACS, we found robust persistence of MMCs in the lung and trachea to D21 even though total cell numbers, reflecting the inflammation-induced cellular infiltrate, fell off in the first week after challenge. By histology, MMCs accumulate in the large bronchi of the lung with a peak value that was maintained from
D7 to 21, declined to half that level by $\mathrm{D} 42$, and returned to near baseline levels by D77. In the trachea, the level peaked at D14 and then declined slowly with some persistence even at D77 after challenge. These differences in survival suggest a role for unidentified tissue factors. Despite the appreciable but transient increase in airway MMCs with allergic lung inflammation, there is no change in numbers of CMCs. Thus, the remodeling of airways associated with MC hyperplasia during chronic allergen challenge likely includes pathobiology because of the sustained presence of induced MMCs. ${ }^{47,48}$

In humans, MCs are classically subdivided into epithelial $\mathrm{MC}_{\mathrm{T}}$, containing tryptase, and constitutive $\mathrm{MC}_{\mathrm{TC}}$, containing both tryptase and chymase and located predominantly in the skin and small intestinal submucosa. ${ }^{49}$ Allergic asthmatic inflammation is associated with increases in epithelial, submucosal, and smooth muscle MCs of both $\mathrm{MC}_{\mathrm{T}}$ and $\mathrm{MC}_{\mathrm{TC}}$ phenotypes. ${ }^{23,24}$ The $\mathrm{MC}_{\mathrm{T}} \mathrm{s}$ are sensitive to inhaled steroid treatment, whereas the $\mathrm{MC}_{\mathrm{TC}} \mathrm{S}$ are resistant to reduction by inhaled or systemic steroid treatment in patients with moderate and severe asthma. ${ }^{23,50}$ Here, we find that steroid treatment during the challenge or induction phase suppresses the inflammation-dependent recruitment of MCps and appearance of less granulated MMCs, whereas steroid treatment has no effect when delayed until the MMCs are established.

The two classic MC subclasses show distinct developmental patterns in the mouse. The development of the long-lived CMCs is controlled by innate mechanisms following the late embryonic seeding of the fetus from fetal liver-derived progenitors. ${ }^{9} 16$ We now show that in the airways, transient MMCs, induced by adaptive immunity, are derived from MCps in the stable presence of CMCs as seen for trachea. Further, although the numbers of recruited MCps and the associated inflammatory response of $\mathrm{CD} 45^{+}$lung leukocytes can be suppressed by steroid treatment during Ag challenge, steroid treatment delayed until MMCs are induced has no effect on their numbers. From an evolutionary viewpoint, the existence of two separate mature populations, innate and adaptive, with different distributions within tissues and phenotypic differences but a common lineage implies a functional importance for each that is likely beyond what has been recognized.

\section{METHODS}

Mice. Seven- to 18 -week-old BALB/c mice were obtained from Taconic Farms (Hudson, NY). The use of mice for these studies was in accordance with institutional guidelines with review and approval by the Animal Care and Use Committee of the Dana Farber Cancer Institute.

Reagents. Fluorescently labeled $\mathrm{mAbs}$ directed against FceRI $\alpha$ (MAR-1), Kit (2B8), CD3 (145-2C11), CD19 (6D5), CD4 (GK1.5), CD11b (M1/70), CD45 (30F-11), CD49d (R1-2), and $\beta 1$ (HMß1-1) were obtained from BioLegend (San Diego, CA). Fluorescently labeled anti- $\beta 7$ integrin (M293) and anti- $\alpha$ E integrin mAb (M290), as well as blocking anti- $\alpha \mathrm{E}$ integrin $\mathrm{mAb}(\mathrm{M} 290)$ were obtained from $\mathrm{BD}$ Biosciences (San Diego, CA). Anti-IgE mAb (23G3) was obtained from eBioscience (San Diego, CA). The anti- $\alpha 4$ integrin blocking antibody (PS/2) was obtained from EMD Millipore (Temecula, CA). All blocking mAbs containing sodium azide were dialyzed against HBSS to eliminate the azide. USP reference standard Prednisone was 
obtained from Sigma-Aldrich (St Louis, MO), reconstituted in dimethyl sulfoxide and diluted 1:2000 with sterile HBSS.

Ovalbumin sensitization and ovalbumin aerosol challenge protocol. Individual groups of two to three mice were sensitized and challenged (Supplementary Figure 2) as described previously. ${ }^{28,31}$ After 7 daily challenges (days 1-7), mice were killed on day 8 (designated D1 after challenge), day 15 (D7), day 22 (D14), day 28 (D21), day 50 (D42), and day 85 (D77) for analysis by FACS and histology.

Steroid administration protocol. For the acute disease protocol, we administered prednisone $\left(10 \mathrm{mg} \mathrm{kg}^{-1}\right)$ or HBSS i.p. just before the ovalbumin challenges of sensitized mice starting with the first challenge and then every other day for 7 days. For the delayed administration protocol, sensitized mice were challenged with ovalbumin and prednisone administration was initiated $\sim 24 \mathrm{~h}$ after the last challenge (D1) and then administered at the same dose every other day until the mice were killed on D7 after challenge.

Antibody blocking protocol. To evaluate the role $\alpha 4$ and $\alpha \mathrm{E}$ integrins in pulmonary recruitment of MCs, $100 \mu \mathrm{g}$ of isotype control or blocking $\mathrm{mAb}$, in $100 \mu \mathrm{l}$ of HBSS, was administered i.p. to sensitized mice. Injections were given daily starting on the first day of aerosolized ovalbumin challenges and mice were killed for FACS analysis 1 day after the last challenge, D1.

Identification of MCs by FACS and histology. Lungs were perfused with $10 \mathrm{ml}$ of cold HBSS through the right ventricle, ${ }^{28}$ removed intact, physically dissociated with a gentleMACS Dissociator (Miltenyi Biotec, San Diego, CA) in $10 \mathrm{ml}$ of RPMI containing 5\% fetal calf serum, and then enzymatically dissociated. Tracheas were finely chopped with scalpels, physically dissociated using the gentleMACS in $10 \mathrm{ml}$ RPMI with 5\% fetal calf serum, and then enzymatically dissociated. For the enzymatic dissociation, lung and trachea fragments were incubated with $500 \mathrm{U} \mathrm{ml}^{-1}$ collagenase (CLS-IV; Worthington Biochemical, Lakewood, NJ) and $0.02 \mathrm{mg} \mathrm{ml}^{-1}$ DNAse I (SigmaAldrich) in RPMI with $5 \%$ fetal calf serum at $37^{\circ} \mathrm{C}$ for 60 min with agitation at 200 r.p.m. Single cells were harvested by adding another $10 \mathrm{ml}$ of complete RPMI ( $10 \%$ fetal calf serum, L-glutamine, penicillin, streptomycin, gentamicin, HEPES buffer, sodium pyruvate, and 2mercaptoethanol (Sigma-Aldrich), and then collected by centrifugation. Lung single-cell suspensions were spun through $44 \%$ Percoll (Sigma-Aldrich) at $400 \mathrm{~g}$ for $20 \mathrm{~min}$ and the supernatant containing epithelial cells was discarded. Erythrocytes were hypotonically lysed $\left(30 \mathrm{~s}\right.$ in $0.1 \mathrm{mM}$ EDTA, $2.0 \mathrm{gl}^{-1}$ potassium bicarbonate, $16.6 \mathrm{gl}^{-1}$ ammonium chloride). Viable cell yields were determined using Trypan blue on a hemocytometer. Trachea and lung cell suspensions were washed with HBSS, and prepared for analysis by flow cytometry. Single-cell suspensions from the spleen and peritoneal cavity were obtained as described previously. ${ }^{17}$ Dead cells were excluded using the Zombie Aqua fixable viability kit (BioLegend). Nonspecific mAb uptake was blocked with CD16/32 (2.4G2) (BD Biosciences) for $10 \mathrm{~min}$, and the appropriate $\mathrm{mAbs}$ were added for $30 \mathrm{~min}$. Flow cytometry was performed as described previously. ${ }^{17} \mathrm{~B}$ cells, $\mathrm{T}$ cells, and macrophages were excluded using $\mathrm{mAb}$ against CD19, CD3, CD4, and CD11b after identification of CD45 ${ }^{+}$cells.

Histologic assessment of MCs in the tissues using chloroacetate esterase reactivity was performed as described previously. ${ }^{10,28}$

Statistics. Data are expressed as the mean \pm s.e.m. when derived from three or more values. For statistical analysis of differences between the groups, results were compared using a one-way analysis of variance followed by Student's $t$-test if the analysis of variance $P$-value was $<0.05$. Significance was determined with the Mann-Whitney $U$-test when the values did not follow a normal distribution. $P$-values $<0.05$ were considered statistically significant and the following designations were used: ${ }^{*} P<0.05,{ }^{* *} P<0.01$, and ${ }^{* *} P<0.001$. Statistical analysis was performed with Prism software (GraphPad Software, San Diego, CA).
Supplementary Material is linked to the online version of the paper at http://www.nature.com/mi

\section{ACKNOWLEDGMENTS}

We thank Dr Juying Lai for the excellent technical assistance in performing all of the histochemical staining. This work was supported by grants from the National Institutes of Health: P50-GM52585, R01-AI083516, and T32Al007306, and by the Joycelyn C. Austen Fund for Career Development of Women Physician Scientists.

\section{DISCLOSURE}

The authors declared no conflict of interest.

c) 2015 Society for Mucosal Immunology

\section{REFERENCES}

1. Mota, I. \& Vugman, I. Effects of anaphylactic shock and compound $48 / 80$ on the mast cells of the guinea pig lung. Nature 177, 427-429 (1956).

2. Paterson, N.A., Wasserman, S.I., Said, J.W. \& Austen, K.F. Release of chemical mediators from partially purified human lung mast cells. J. Immunol. 117, 1356-1362 (1976).

3. Razin, E., Mencia-Huerta, J.M., Lewis, R.A., Corey, E.J. \& Austen, K.F. Generation of leukotriene C4 from a subclass of mast cells differentiated in vitro from mouse bone marrow. Proc. Natl. Acad. Sci. USA 79, 4665-4667 (1982).

4. Enerback, L. Mast cells in rat gastrointestinal mucosa. 2. Dye-binding and metachromatic properties. Acta Pathol. Microbiol. Scand. 66, 303-312 (1966).

5. Fukuzumi, T. et al. Differences in irradiation susceptibility and turnover between mucosal and connective tissue-type mast cells of mice. Exp. Hematol. 18, 843-847 (1990).

6. Mayrhofer, G. \& Bazin, H. Nature of the thymus dependency of mucosal mast cells. III. Mucosal mast cells in nude mice and nude rats, in B rats and in a child with the Di George syndrome. Int. Arch. Allergy Appl. Immunol. 64, 320-331 (1981).

7. Irani, A.M. et al. Deficiency of the tryptase-positive, chymase-negative mast cell type in gastrointestinal mucosa of patients with defective T lymphocyte function. J. Immunol. 138, 4381-4386 (1987).

8. Ruitenberg, E.J. \& Elgersma, A. Absence of intestinal mast cell response in congenitally athymic mice during Trichinella spiralis infection. Nature 264, 258-260 (1976).

9. Sonoda, T., Hayashi, C. \& Kitamura, Y. Presence of mast cell precursors in the yolk sac of mice. Dev. Biol. 97, 89-94 (1983).

10. Friend, D.S. et al. Mast cells that reside at different locations in the jejunum of mice infected with Trichinella spiralis exhibit sequential changes in their granule ultrastructure and chymase phenotype. J. Cell Biol. 135, 279-290 (1996).

11. Sonoda, T., Ohno, T. \& Kitamura, Y. Concentration of mast-cell progenitors in bone marrow, spleen, and blood of mice determined by limiting dilution analysis. J. Cell. Physiol. 112, 136-140 (1982).

12. Parmentier, H.K., Teppema, J.S., van Loveren, H., Tas, J. \& Ruitenberg, E.J. Effect of a Trichinella spiralis infection on the distribution of mast cell precursors in tissues of thymus-bearing and non-thymus-bearing (nude) mice determined by an in vitro assay. Immunology 60, 565-571 (1987).

13. Pennock, J.L. \& Grencis, R.K. In vivo exit of c-kit +/CD49dhi/\{beta\}7 + mucosal mast cell precursors from the bone marrow following infection with the intestinal nematode Trichinella spiralis. Blood 103, 2655-2660 (2003).

14. Arinobu, Y. et al. Developmental checkpoints of the basophil/mast cell lineages in adult murine hematopoiesis. Proc. Natl. Acad. Sci. USA 102, 18105-18110 (2005).

15. Chen, C.C., Grimbaldeston, M.A., Tsai, M., Weissman, I.L. \& Galli, S.J. Identification of mast cell progenitors in adult mice. Proc. Natl. Acad. Sci. USA 102, 11408-11413 (2005).

16. Rodewald, H.R., Dessing, M., Dvorak, A.M. \& Galli, S.J. Identification of a committed precursor for the mast cell lineage. Science 271, 818-822 (1996). 
17. Liu, A.Y. et al. Mast cells recruited to mesenteric lymph nodes during helminth infection remain hypogranular and produce $\mathrm{LL}-4$ and $\mathrm{L}-6$. J. Immunol. 190, 1758-1766 (2013).

18. Tomioka, H. \& Ishizaka, K. Mechanisms of passive sensitization. II. Presence of receptors for IgE on monkey mast cells. J. Immunol. 107, 971-978 (1971).

19. lemura, A., Tsai, M., Ando, A., Wershil, B.K. \& Galli, S.J. The c-kit ligand, stem cell factor, promotes mast cell survival by suppressing apoptosis. Am. J. Pathol. 144, 321-328 (1994).

20. Abonia, J.P. et al. Alpha-4 integrins and VCAM-1, but not MAdCAM-1, are essential for recruitment of mast cell progenitors to the inflamed lung. Blood 108, 1588-1594 (2006).

21. Gurish, M.F. et al. Intestinal mast cell progenitors require CD49dbeta7 (alpha4beta7 integrin) for tissue-specific homing. J. Exp. Med. 194, 1243-1252 (2001).

22. Ando, A., Martin, T.R. \& Galli, S.J. Effects of chronic treatment with the c-kit ligand, stem cell factor, on immunoglobulin E-dependent anaphylaxis in mice. Genetically mast cell-deficient SI/SId mice acquire anaphylactic responsiveness, but the congenic normal mice do not exhibit augmented responses. J. Clin. Invest. 92, 1639-1649 (1993).

23. Balzar, S. et al. Mast cell phenotype, location, and activation in severe asthma: data from the severe asthma research program. Am. J. Respir. Crit. Care Med. 183, 299-309 (2011).

24. Brightling, C.E. et al. Mast-cell infiltration of airway smooth muscle in asthma. N. Engl. J. Med. 346, 1699-1705 (2002).

25. Munger, J.S. et al. The integrin alpha $v$ beta 6 binds and activates latent TGF beta 1: a mechanism for regulating pulmonary inflammation and fibrosis. Cell 96, 319-328 (1999).

26. Yu, M. et al. Mast cells can promote the development of multiple features of chronic asthma in mice. J. Clin. Invest. 116, 1633-1641 (2006).

27. Yu, M. et al. Identification of an IFN-gamma/mast cell axis in a mouse model of chronic asthma. J. Clin. Invest. 121, 3133-3143.

28. Xing, W., Austen, K.F., Gurish, M.F. \& Jones, T.G. Protease phenotype of constitutive connective tissue and of induced mucosal mast cells in mice is regulated by the tissue. Proc. Natl. Acad. Sci. USA 108, 14210-14215 (2011).

29. Miller, H.R. \& Pemberton, A.D. Tissue-specific expression of mast cell granule serine proteinases and their role in inflammation in the lung and gut. Immunology 105, 375-390 (2002).

30. Hallgren, J. et al. Pulmonary CXCR2 regulates VCAM-1 and antigeninduced recruitment of mast cell progenitors. Proc. Natl. Acad. Sci. USA 104, 20478-20483 (2007).

31. Jones, T.G. et al. Antigen-induced increases in pulmonary mast cell progenitor numbers depend on IL-9 and CD1d-restricted NKT cells. J. Immunol. 183, 5251-5260 (2009).

32. Lantz, C.S. \& Huff, T.F. Murine KIT + lineage - bone marrow progenitors express Fc gamma-RIl but do not express Fc epsilon-RI until mast cell granule formation. J. Immunol. 154, 355-362 (1995).

33. Jamur, M.C. et al. Identification and characterization of undifferentiated mast cells in mouse bone marrow. Blood 105, 4282-4289 (2005).

34. Kaieda, S. et al. Synovial fibroblasts promote the expression and granule accumulation of tryptase via interleukin-33 and its receptor ST-2 (IL1RL1). J. Biol. Chem. 285, 21478-21486 (2010).
35. Levi-Schaffer, F., Austen, K.F., Gravallese, P.M. \& Stevens, R.L. Coculture of interleukin 3-dependent mouse mast cells with fibroblasts results in a phenotypic change of the mast cells. Proc. Natl. Acad. Sci. USA 83, 64856488 (1986).

36. Levi-Schaffer, F. et al. Mouse bone marrow-derived mast cells cocultured with fibroblasts. Morphology and stimulation-induced release of histamine, leukotriene B4, leukotriene C4, and prostaglandin D2. J. Immunol. 139, 3431-3441 (1987).

37. Craig, S.S., Schechter, N.M. \& Schwartz, L.B. Ultrastructural analysis of human Tand TC mast cells identified by immunoelectron microscopy. Lab. Invest. 58, 682-691 (1988).

38. Weidner, N. \& Austen, K.F. Ultrastructural and immunohistochemical characterization of normal mast cells at multiple body sites. J. Invest. Dermatol. 96, 26S-30S (1991).

39. Shaw, L.M., Turner, C.E. \& Mercurio, A.M. The alpha 6 A beta 1 and alpha $6 B$ beta 1 integrin variants signal differences in the tyrosine phosphorylation of paxillin and other proteins. J. Biol. Chem. 270, 23648-23652 (1995).

40. Schon, M.P. et al. Mucosal T lymphocyte numbers are selectively reduced in integrin alpha E (CD103)-deficient mice. J. Immunol. 162, 6641-6449 (1999).

41. Wright, S.H. et al. Transforming growth factor-beta1 mediates coexpression of the integrin subunit alphaE and the chymase mouse mast cell protease-1 during the early differentiation of bone marrow-derived mucosal mast cell homologues. Clin. Exp. Allergy 32, 315-324 (2002).

42. Ducharme, L.A. \& Weis, J.H. Modulation of integrin expression during mast cell differentiation. Eur. J. Immunol. 22, 2603-2607 (1992).

43. Smith, T.J. et al. Murine M290 integrin expression modulated by mast cell activation. Immunity 1, 393-403 (1994).

44. Brown, J.K. et al. Expression of integrin-alphaE by mucosal mast cells in the intestinal epithelium and its absence in nematode-infected mice lacking the transforming growth factor-beta1-activating integrin alphavbeta6. Am. J. Pathol. 165, 95-106 (2004).

45. Zhao, W., Gomez, G., Yu, S.H., Ryan, J.J. \& Schwartz, L.B. TGF-beta1 attenuates mediator release and de novo Kit expression by human skin mast cells through a Smad-dependent pathway. J. Immunol. 181, 7263-7272 (2008).

46. Sugimoto, $\mathrm{K}$. et al. The alphavbeta6 integrin modulates airway hyperresponsiveness in mice by regulating intraepithelial mast cells. J. Clin. Invest. 122, 748-758 (2012)

47. Bradding, P., Walls, A.F. \& Holgate, S.T. The role of the mast cell in the pathophysiology of asthma. J. Allergy Clin. Immunol. 117, 1277-1284 (2006).

48. Kearley, J. et al. IL-9 governs allergen-induced mast cell numbers in the lung and chronic remodeling of the airways. Am. J. Respir. Crit. Care Med. 183, 865-875 (2011).

49. Irani, A.A., Schechter, N.M., Craig, S.S., DeBlois, G. \& Schwartz, L.B. Two types of human mast cells that have distinct neutral protease compositions. Proc. Natl. Acad. Sci. USA 83, 4464-4468 (1986).

50. Bentley, A.M. et al. Prednisolone treatment in asthma. Reduction in the numbers of eosinophils, $T$ cells, tryptase-only positive mast cells, and modulation of IL-4, IL-5, and interferon-gamma cytokine gene expression within the bronchial mucosa. Am. J. Respir. Crit. Care Med. 153, 551-556 (1996). 